\title{
Physical education teaching quality fuzzy analysis of the relationship with teachers
}

\author{
Chao Chen ${ }^{1,}$, Bing Zhang ${ }^{2, b}$ \\ ${ }^{1}$ Institute of Physical Education, Jilin Normal University, Siping 136000, China \\ 2Institute of Physical Education, Huanggang Normal University, Huangzhou 438000, China
}

\begin{abstract}
Physical health of teenagers is closely connected with professional sports teachers' guidance. China's colleges and universities sports education professional teaching quality is declining, it will pose a serious challenge to the physical and mental health of teenagers. This article from the perspective of teachers, the quality problems in the teaching of research university sports education professional, using fuzzy clustering analysis method, analyzes the research object, and gives the method to cluster analysis of figure. The results of the analysis index of Beijing sports university and is the most close to shenyang sports colleges and universities.
\end{abstract}

\section{Introduction}

Teenager is the future of a country, the hope of a nation. Professional sports teachers cultivation is a basic guarantee of teenager physical exercises. However, with institutions of higher learning constantly expanding enrollment, each major teaching quality is hard to ensure, especially for sports dance major teaching quality, which constitutes a certain threaten to Chinese future teenager health growth [1-3].

By referencing lots of documents, the paper based on formers research, starts from faculty structure perspective, studies on Chinese universities undergraduate physical education major teaching quality, and analyzes faculty overall structure.

\section{Evaluation model establishment}

Chinese universities undergraduate physical education major teaching quality has inseparable relations to faculty overall structure. Faculty overall structure contains professional title structure, qualification structure, age structure and academic structure. The establishment of the model aims to make classification of the three sports institutions of higher learning, and meanwhile presents classification path so as to easy to better study on the problems in later period [4-6].

Data is from "Discuss regular institution of higher learning physical education undergraduate program teaching quality guarantee". In above mentioned four factors, define standard factors, professional title structure takes advanced professional and technical posts teachers proportions as standard, qualification structure takes proportion of teachers with master and doctorate as standard, age structure takes proportions of young and mid-aged teachers that below forty-five years old as standard, academic structure takes proportions of teachers graduate in external schools as standard. In order to be convenient for observing, draw original data as broken line chart to make comparison, as Figure 1 shows.

From Figure 1, we can see that in the five research objects, age structure differences are not big; it is qualification structure that has significant differences.

In daily life, we tend to need classifying multiple indicators according to certain criterions. But in most cases, classification limits are not very obvious, therefore fuzzy clustering analysis application in practice is very widely [7].

It is clear $\mathrm{U}=\left\{\mathrm{x}_{1}, \mathrm{x}_{2}, \mathrm{x}_{3}, \mathrm{x}_{4}, \mathrm{x}_{5}\right\}$ make classification on these five traditional sports events, select self proportions as standard, and look for three institutions of higher learning (five groups of data) classification path.

At first, according to Table 1 data, it constructs characteristic indicator matrix $X^{*}$.

$$
X^{*}=\left[\begin{array}{rrrr}
50.36 & 47.26 & 73.01 & 35.63 \\
47.84 & 53.14 & 71.96 & 41.18 \\
42.70 & 34.20 & 75.70 & 48.20 \\
47.10 & 52.90 & 75.30 & 50.40 \\
35.53 & 42.49 & 71.40 & 48.70
\end{array}\right]
$$

Adopt maximum normalization method to normalize original data as:

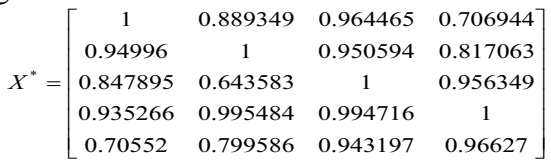

a,b Corresponding author: ${ }^{a} 398704001 @ q q . c o m ;$

b tiyuxi@qq.com 
And then use maxi-min method to construct fuzzy similar matrix, the computational process is as following:

$r_{12}=\frac{\sum_{k=1}^{4}\left(x_{1 k} \wedge x_{2 k}\right)}{\sum_{k=1}^{4}\left(x_{1 k} \vee x_{2 k}\right)}=\frac{0.94996+0.889349+0.950594+0.706944}{1+1+0.964465+0.817063}=0.9245$

$r_{23}=\frac{\sum_{k=1}^{4}\left(x_{2 k} \wedge x_{3 k}\right)}{\sum_{k=1}^{4}\left(x_{2 k} \vee x_{3 k}\right)}=\frac{0.847895+0.643583+0.950594+0.807063}{0.94996+1+1+0.956349}=0.8343$

$r_{24}=\frac{\sum_{k=1}^{4}\left(x_{2 k} \wedge x_{4 k}\right)}{\sum_{k=1}^{4}\left(x_{2 k} \vee x_{4 k}\right)}=\frac{0.935266+0.995484+0.950594+0.817063}{0.94996+1+1+0.994716}=0.9376$

$r_{34}=\frac{\sum_{k=1}^{4}\left(x_{3 k} \wedge x_{4 k}\right)}{\sum_{k=1}^{4}\left(x_{3 k} \vee x_{4 k}\right)}=\frac{0.70552+0.799586+0.943197+0.96627}{0.935266+0.995484+0.994716+1}=0.8699$

Others $\mathrm{r}_{\mathrm{ij}}$ computational methods are as above.

$$
R=\left[\begin{array}{ccccc}
1 & 0.9245 & 0.8224 & 0.8762 & 0.8260 \\
0.9245 & 1 & 0.8343 & 0.9376 & 0.8489 \\
0.8224 & 0.8343 & 1 & 0.8699 & 0.8990 \\
0.8762 & 0.9376 & 0.8699 & 1 & 0.8699 \\
0.8260 & 0.8489 & 0.8990 & 0.8699 & 1
\end{array}\right]
$$

Use squares method to compound transitive closure $t(R)=R^{4}$ and get:

$$
t(R)=\left[\begin{array}{ccccc}
1 & 0.9247 & 0.8758 & 0.9247 & 0.8758 \\
0.9247 & 1 & 0.8758 & 0.9376 & 0.8990 \\
0.8758 & 0.8758 & 1 & 0.8758 & 0.8990 \\
0.9247 & 0.9376 & 0.8758 & 1 & 0.8990 \\
0.8758 & 0.8990 & 0.8990 & 0.8990 & 1
\end{array}\right]
$$

$\mathrm{t}(\mathrm{R})$ elements ranks according to size are: $1>0.94>0.92>0.90>0.88$

For above process, use partial dynamical clustering graph to express as Figure 2.

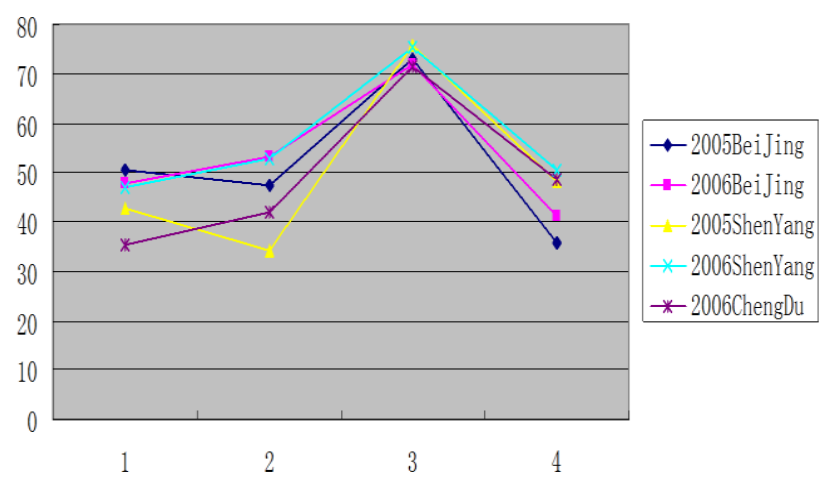

Figure 1. The raw data line chart.

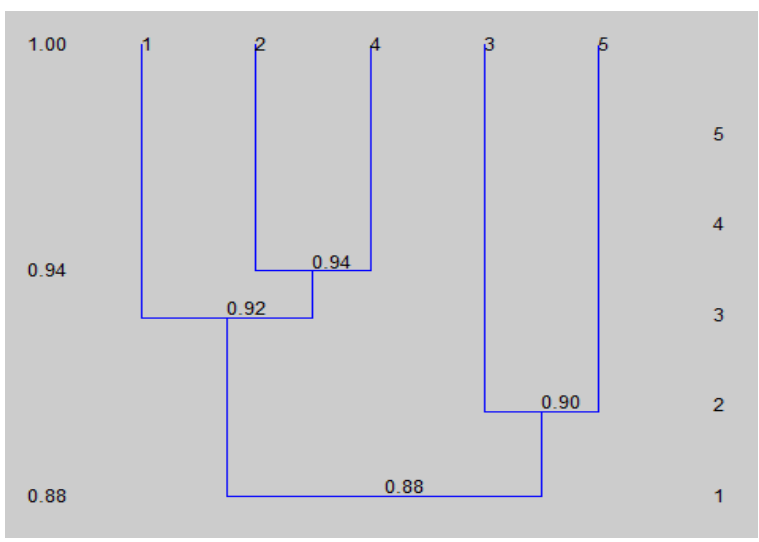

Figure 2. The figure of part of the dynamic clustering.

In Figure 2, "1" represents Beijing sports institutions of higher learning in 2005 ,"2"represents Beijing sports institutions of higher learning in 2006 , 3 " represents Shenyang sports institutions of higher learning in 2005 ,"4" represents Shenyang sports institutions of higher learning in 2006 , 5 " represents Chengdu sports institutions of higher learning in 2006. From Figure, it is clear that indicators of Beijing sports institutions of higher learning in 2006 and get closest to that of Shenyang sports universities in 2007 , it can be firstly clustered as one type.

\section{Conclusions}

The paper proceeded fuzzy clustering is adopting transitive closure method; its steps are clearly and easier to program with strong operability. In daily life, lots of problems have no clearly limits; therefore, the method application range is wide and well adapted. But due to fuzzy clustering analysis needs to determine in advance about how kinds it classifies, once number of classification determine is fault, the result accuracy will reduce and then it is hard to ensure objectivity. Therefore, in general, people will carry out classification 
handling with research objects according to dynamic clustering analysis chart.

The paper applies fuzzy clustering analysis into physical education quality evaluation, carries out fuzzy clustering analysis of five researched objects, and provides fuzzy clustering analysis chart. The figure can clearly indicate clustering paths, which provides help for the kind of problems future researching.

\section{References}

1. X.Y. Xu, Journal Of Anhui University 30 (2006).
2. N. Chen, Journal Of Yunnan Finance And Trade Institute 21 (2005).

3. X.G. Wang, Research On Development 5 (2007).

4. L.W. Fan, J.Y. Liang, Value Engineering 25 (2006). 29-31.

5. B.M. Su, Z.X. Liu, C.M. Liu, Journal Of Jinan University 12 (2002).

6. J.H. Lu, Journal Of Anhui University(Philosophy \& Social Sciences) 30 (2006).

7. X. Chen, Z. Jin, G. Lin, Journal Of Coastal Research, 73 (2015).

8. P. Wang, Q.Q. Sun, Journal Of Mechanical Engineering Research And Developments 38 (2015). 